Article

\title{
Systematic Analysis of Gibberellin Pathway Components in Medicago truncatula Reveals the Potential Application of Gibberellin in Biomass Improvement
}

\author{
Hongfeng Wang $1,2, * \mathbb{0}$, Hongjiao Jiang ${ }^{2}$, Yiteng $\mathrm{Xu}^{2}$, Yan Wang ${ }^{2}$, Lin $\mathrm{Zhu}^{2}$, Xiaolin $\mathrm{Yu}^{2}$, \\ Fanjiang Kong ${ }^{1}$, Chuanen Zhou ${ }^{2}\left(\mathbb{D}\right.$ and Lu Han ${ }^{2, *}$ \\ 1 School of Life Science, Guangzhou University, Guangzhou 510006, China; kongfj@iga.ac.cn \\ 2 The Key Laboratory of Plant Development and Environmental Adaptation Biology, Ministry of Education, \\ School of Life Science, Shandong University, Qingdao 266101, China; 201611650@mail.sdu.edu.cn (H.J.); \\ 201411612@mail.sdu.edu.cn (Y.X.); 201812415@mail.sdu.edu.cn (Y.W.); 201832474@mail.sdu.edu.cn (L.Z.); \\ yuxiaolin@sdu.edu.cn (X.Y.); czhou@sdu.edu.cn (C.Z.) \\ * Correspondence: wanghf@gzhu.edu.cn (H.W.); lhan@sdu.edu.cn (L.H.)
}

Received: 27 August 2020; Accepted: 27 September 2020; Published: 29 September 2020

\begin{abstract}
Gibberellins (GAs), a class of phytohormones, act as an essential natural regulator of plant growth and development. Many studies have shown that GA is related to rhizobial infection and nodule organogenesis in legume species. However, thus far, GA metabolism and signaling components are largely unknown in the model legume Medicago truncatula. In this study, a genome-wide analysis of GA metabolism and signaling genes was carried out. In total 29 components, including $8 M t G A 200 x$ genes, $2 M t G A 3 o x$ genes, $13 M t G A 2 o x$ genes, $3 M t G I D 1$ genes, and $3 M t D E L L A$ genes were identified in $M$. truncatula genome. Expression profiles revealed that most members of MtGAox, MtGID1, and MtDELLA showed tissue-specific expression patterns. In addition, the GA biosynthesis and deactivation genes displayed a feedback regulation on GA treatment, respectively. Yeast two-hybrid assays showed that all the three MtGID1s interacted with MtDELLA1 and MtDELLA2, suggesting that the MtGID1s are functional GA receptors. More importantly, $M$. truncatula exhibited increased plant height and biomass by ectopic expression of the MtGA20ox1, suggesting that enhanced GA response has the potential for forage improvement.
\end{abstract}

Keywords: Medicago truncatula; gibberellins; expression analysis; forage improvement

\section{Introduction}

Gibberellins (GAs), a class of well-known phytohormones, play important roles in regulating growth and development throughout the life cycle, such as seed germination, stem/internode elongation, leaf expansion, flowering, fruit development, and nodule organogenesis in legume [1-8]. Accumulating evidence has elucidated the molecular mechanism of GA biosynthesis, metabolism, and signaling in plants [9-12]. In higher plants, GA synthesis can be divided into three steps (Figure S1): (i) biosynthesis of ent-kaurene from trans-geranyl-geranyl diphosphate (trans-GGDP) by ent-copalyl diphosphate synthase (CPS) and ent-kaurene synthase (KS) in plastids; (ii) conversion of ent-kaurene to ent-kaurenic acid by ent-kaurene oxidase (KO), and (iii) conversion of ent-kaurenic acid to bioactive GAs by ent-kaurenoic acid oxidase (KAO), GA 20-oxidase (GA20ox), and GA 3-oxidase (GA3ox). Degradation of GA is mainly catalyzed by GA 2-oxidase (GA2ox). GA20ox, GA3ox and GA2ox proteins all belonged to the 2-oxoglutarate-dependent dioxygenase (2-ODDs) family, which containing two domains, DIOX_N and 2OG-FeII_Oxy. The 2OG-FeII_Oxy domain contains the consensus sequence 
NXYPXCXXP and three histidine residues, which are respectively involved in binding the common co-substrate 2-oxoglutarate and $\mathrm{Fe}^{2+}$. The DIOX_N domain contains the LPWKET sequence related to the binding of the GA substrate. Reduction of endogenous bioactive GA content by mutation and down-regulation of GA20ox can generate dwarf phenotypes in diverse species and contributed to the Green Revolution. In rice, SD1 encodes a GA20-oxidase and its mutants show dwarfism and increase in yield [13]. In Arabidopsis, a total of five GA20ox, AtGA20ox1 to AtGA20ox5, are identified and loss-of-function in $A t G A 20 o x 1,-2$, and -3 results in mutants with severe dwarfism, dark green leaves, and delayed flowering [14]. Furthermore, GA3ox also participates in the synthesis of bioactive GAs and the ga3ox1 ga3ox2 double mutants display defects in shoot and root development [15]. Similar to the ga20ox and ga3ox mutants, overexpression of BnGA2ox6 and JcGA2ox6 in Arabidopsis results in GA-deficiency phenotypes, including late flowering, smaller leaves, and shorter siliques $[16,17]$. However, ectopic overexpression of the AtGA20ox1 gene in hybrid aspen results in trees with longer xylem fibers, larger leaves, and increased biomass [18]. Several biochemical and molecular evidence had shown that the transcript levels of GA20ox and GA3ox are regulated by the negative feedback of bioactive GAs, while GA2ox is regulated by positive feedback $[1,19]$. Besides, GA biosynthesis and metabolism are regulated by diverse environmental signals, such as light and cold [20,21].

Once GA is synthesized and present, the GA signal transduction is mediated by GIBBERELLIN INSENSITIVE DWARF 1 (GID1) receptor and DELLA protein. Briefly, GA binding to the soluble GID1 receptor triggers its interaction with DELLA proteins; subsequently DELLA is subject to polyubiquitination by E3 ubiquitin-ligase $\mathrm{SCF}^{\mathrm{SLY} 1 / \mathrm{GID} 2}$ and degradation in the 26S proteasome [22-29]. The rice GID1 is the first and only one identified GA receptor and loss-of-function gid 1 mutations result in a GA-insensitive dwarf phenotype [22,30,31]. Plants overproducing OsGID1 show a GA-hypersensitive phenotype with tall stature, light-green leaves, and fewer tillers [22]. The Arabidopsis genome contains three GID1 homologs, AtGID1A, AtGID1B, and AtGID1C, which are partially redundant in regulating different developmental processes [32-34]. The tomato genome encodes three receptors (SIGID1a, SIGID1b1, and SIGID1b2) and these GA receptors contribute to phenotypic stability under ambient changing environments [35]. DELLA proteins are key regulators of the GA signaling pathway and negatively regulate GA responses [36]. GID1 can directly interact with DELLA domain of DELLA proteins in a GA-dependent manner, and the formation of GA-GID1-DELLA regulatory module promotes the rapid degradation of DELLA repressor [22,32,37-40]. The Arabidopsis genome contains five genes (GAI, RGA, RGL1, RGL2, and RGL3) encoding DELLA proteins, while rice (SLR1) and tomato $(P R O)$ have only one $[23,41-45]$. DELLA proteins are highly conserved in function. Loss-of-function mutants of $R G A, S L R 1$, and $P R O$ show a slender phenotype with stem elongation and leaf expansion [25,43,46-48]. While, gain-of-function mutations in DELLA genes result in plant dwarfism and reduction in GA response [45,49]. The famous wheat "green revolution" Rht genes encode GA-insensitive DELLA proteins that reduce plant height and increase grain number [50,51].

Medicago truncatula is a model species for legume studies and its relative alfalfa (Medicago sativa) is an important forage crop. Increased biomass yield benefits not only the livestock industry but also sustainable agriculture worldwide. Previous studies have shown that altering GA metabolism or signaling contributes to biomass production [18,52-54]. However, knowledge about the molecular features of the GA pathway and response are limited in M. truncatula, let alone the relationship between GA and biomass. In this study, GA metabolism and signaling genes were identified and characterized. Moreover, GA application resulted in improved biomass yield in M. truncatula. Our results provide a theoretical foundation for GA-dependent forage improvement in the future.

\section{Results}

\subsection{Genome-Wide Identification of GA20ox, GA3ox, and GA2ox Genes in M. truncatula}

To identify the GA20ox, GA3ox, and GA2ox genes in M. truncatula, a BLASTP search using the $A$. thaliana AtGA20ox, AtGA3ox, and AtGA2ox genes against $M$. truncatula database was executed. A total 
of 23 candidate genes were obtained in the M. truncatula genome, including $8 M t G A 20 o x, 2 M t G A 3 o x$, and 13 MtGA2ox (Table S1). These MtGAox genes were named based on their closest Arabidopsis orthologs. The gene names, accession numbers, locations, coding sequence (CDS) lengths and the number of the deduced amino acid are summarized in Table S1.

\subsection{Phylogenetic Analysis and Chromosomal Locations of MtGAox Genes}

To establish the evolutionary relationships within the $M t G A o x$ genes, a phylogenetic tree was constructed using the 39 GAox proteins from $M$. truncatula and A. thaliana, including 5 AtGA20ox, 8 MtGA20ox, 4 AtGA3ox, 2 MtGA3ox, 7 AtGA2ox, and 13 MtGA2ox. Based on the phylogenetic analysis, the 39 GAox proteins were divided into four subfamilies (Figure 1): the gibberellin biosynthesis gene family contained the GA20ox and GA3ox genes, and the gibberellin deactivation GA2ox genes could be divided into C19- and C20-GA2ox subgroups.

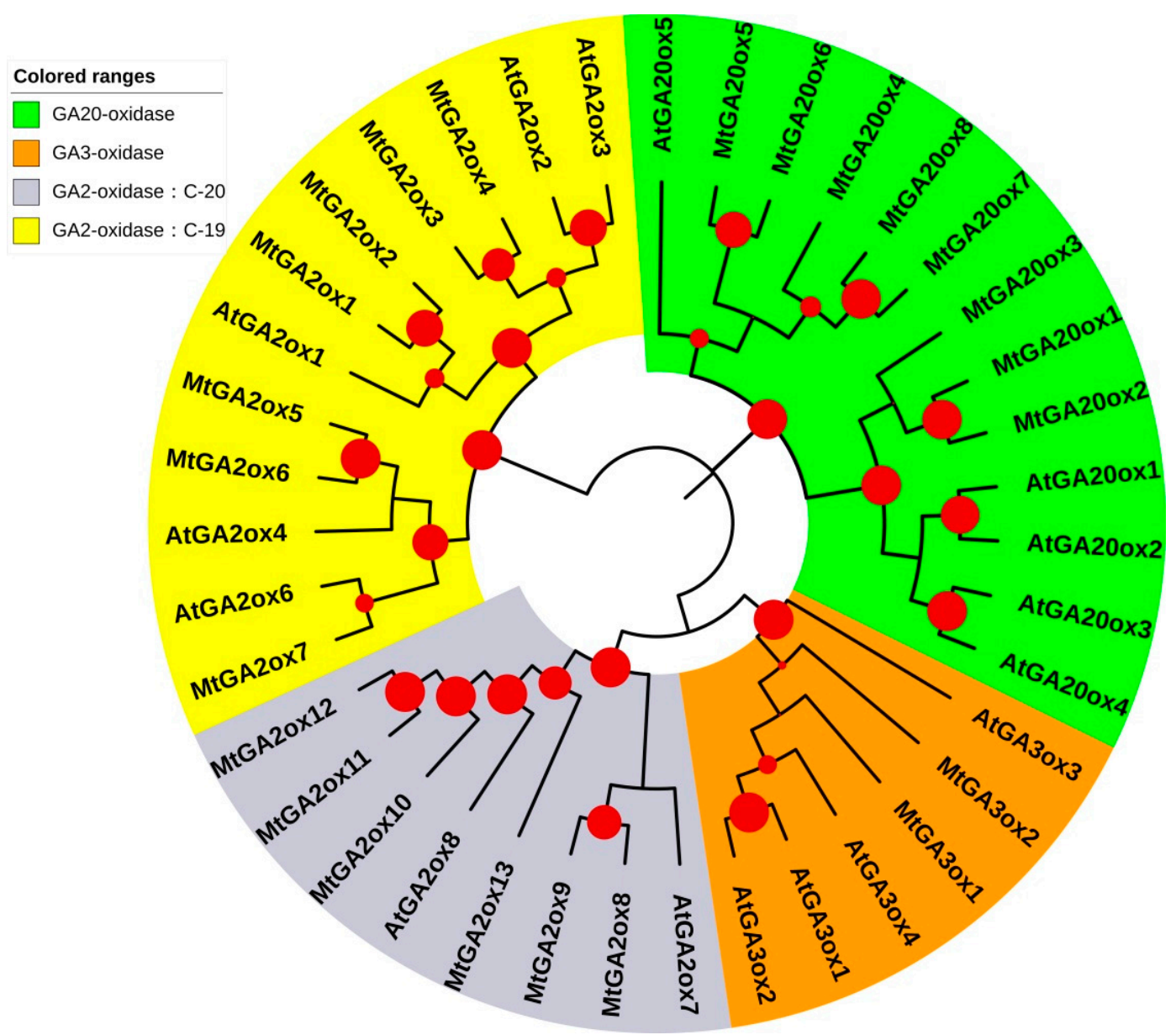

Figure 1. Phylogenetic analysis of GA20oxs, GA3oxs, and GA2oxs in A. thaliana (At) and M.truncatula (Mt). The proteins are grouped into four distinct groups. The phylogenetic tree was constructed using 39 protein sequences from A. thaliana (16) and M.truncatula (23) on iTOLv5 (Interactive Tree of Life; https://itol.embl.de/) online website. The red dots of different sizes (Min size: 5 px; Max size: $30 \mathrm{px}$ ) represent the bootstrap values, ranging from 0.5 to 1 . The branches covered by different color represent the four group proteins.

The 23 MtGAox genes were distributed among 8 chromosomes (Figure S2A). The chromosome 02, 01 and 08, 07, 03 and 04 had six, four, three, and two genes, respectively, while the chromosome 05 and 06 each contained only one. 


\subsection{Gene Structures and Conserved Motifs of MtGAox in M. truncatula}

To get a better understanding of the structural diversity of the MtGAox genes, the structures (exon/intron organization) of MtGAox were analyzed (Figure S2B). MtGA20ox and MtGA2ox genes had the same structure, which all contain three exons. However, all the MtGA3ox genes had two exons. Exon-intron organization indicated that $M t G A 200 x$ and $M t G A 2 o x$ genes were more closely related than MtGA3ox genes.

To obtain a better understanding of the protein sequence characteristics of the MtGAox, MEME search was used to analyze the conserved domains and motifs. Based on the composition of motifs, the MtGAox proteins contained nine different motifs (Figure 2; Figure S3). Motif 1, 2, 3, 4, and 6 were identified as the conserved motif, which was present in every MtGAox protein. Motif 1 and 2 are representative 2OG-FeII_Oxy domain and Motif 3 is representative DIOX_N domain, which are identified in all GAox proteins. Motif 5 was only identified in C-terminal of MtGA20ox proteins, indicating that members within a single subfamily usually exhibit similar motif composition. However, motif 8 was located in the C-terminal part of some members of the MtGA2ox protein family, demonstrating that this motif is related to the functions of these MtGA2ox proteins.

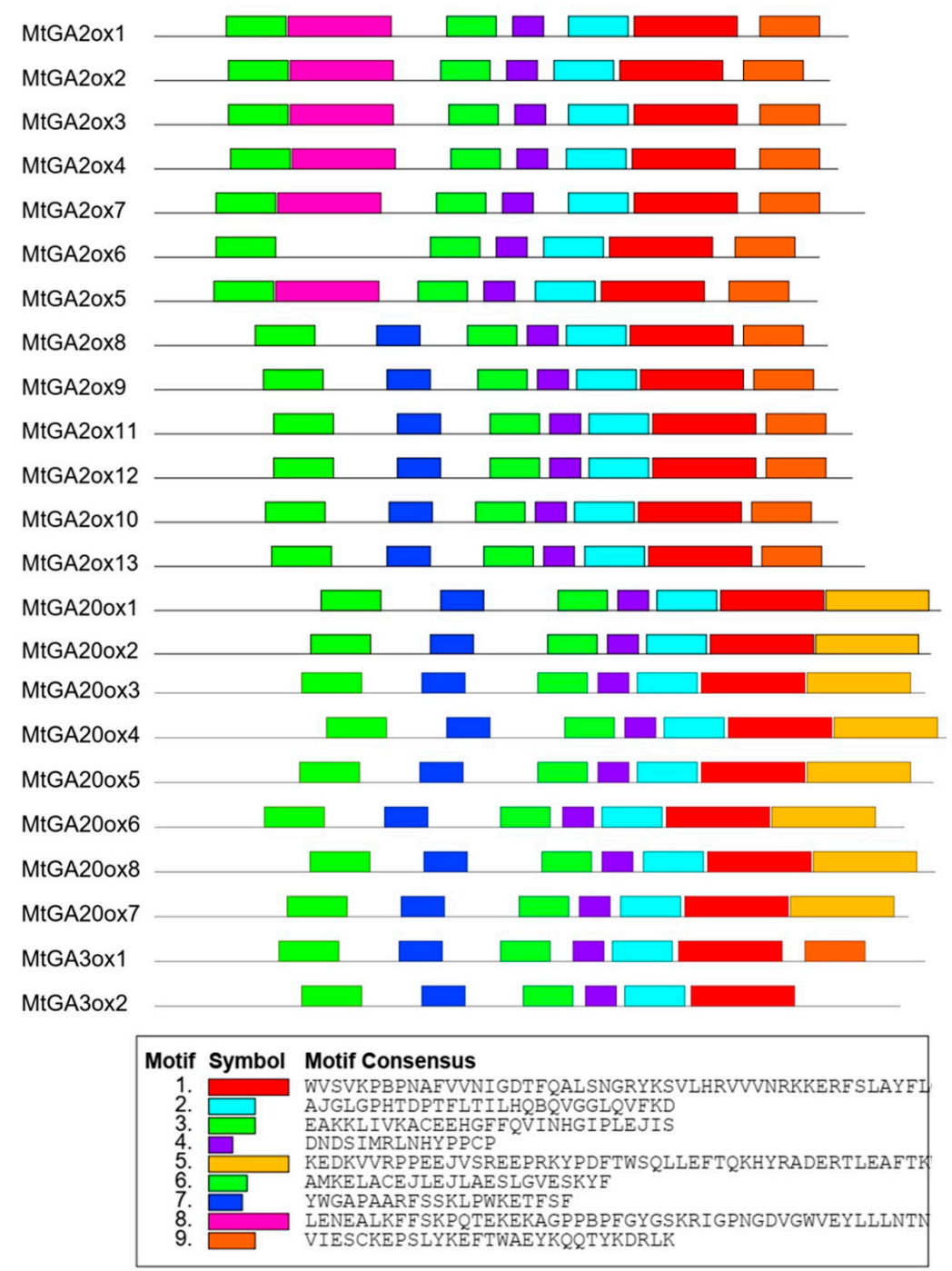

Figure 2. Motifs composition of the MtGA20ox, MtGA3ox, and MtGA2ox proteins. The conserved motifs are predicted by MEME. The different motifs are represented by colored boxes. Motif 3 is representative DIOX_N domain. Motif 1 and motif 2 are representative 2OG-FeII_Oxy domain. 


\subsection{Expression Patterns of MtGAox Genes}

The tissue-specific expression patterns of a gene family can provide information about its possible function. To understand the functional divergence of the $M t G A o x$ genes, we analyzed the expression profiles of the MtGAox genes in different organs/tissues by quantitative RT-PCR (qRT-PCR) and gene expression atlas (Figure 3; Figures $\mathrm{S} 4$ and S5). The results indicated that GA biosynthesis gene MtGA20ox1, MtGA20ox4, MtGA20ox5, MtGA20ox7, and MtGA3ox1 were widely expressed in all tissues examined (Figure 3A). While, MtGA20ox3 and MtGA20ox6 had higher expression levels in stems, MtGA20ox2, MtGA20ox8, and MtGA3ox2 had higher expression levels in flowers, pods, and roots (Figure 3A), respectively, implying important roles of these genes in certain organs or tissues. Most of the GA deactivation genes, such as MtGA2ox1, MtGA2ox2, MtGA2ox6, MtGA2ox8, MtGA2ox9, $M t G A 2 o x 10, M t G A 2 o x 11, M t G A 2 o x 12$, and MtGA2ox13 were widely expressed in all organs tested (Figure 3B). However, $M t G A 20 x 4$ and $M t G A 20 x 7$ were expressed at higher levels in flowers than those in other tissues (Figure 3B), implying their possible involvement in flower development.

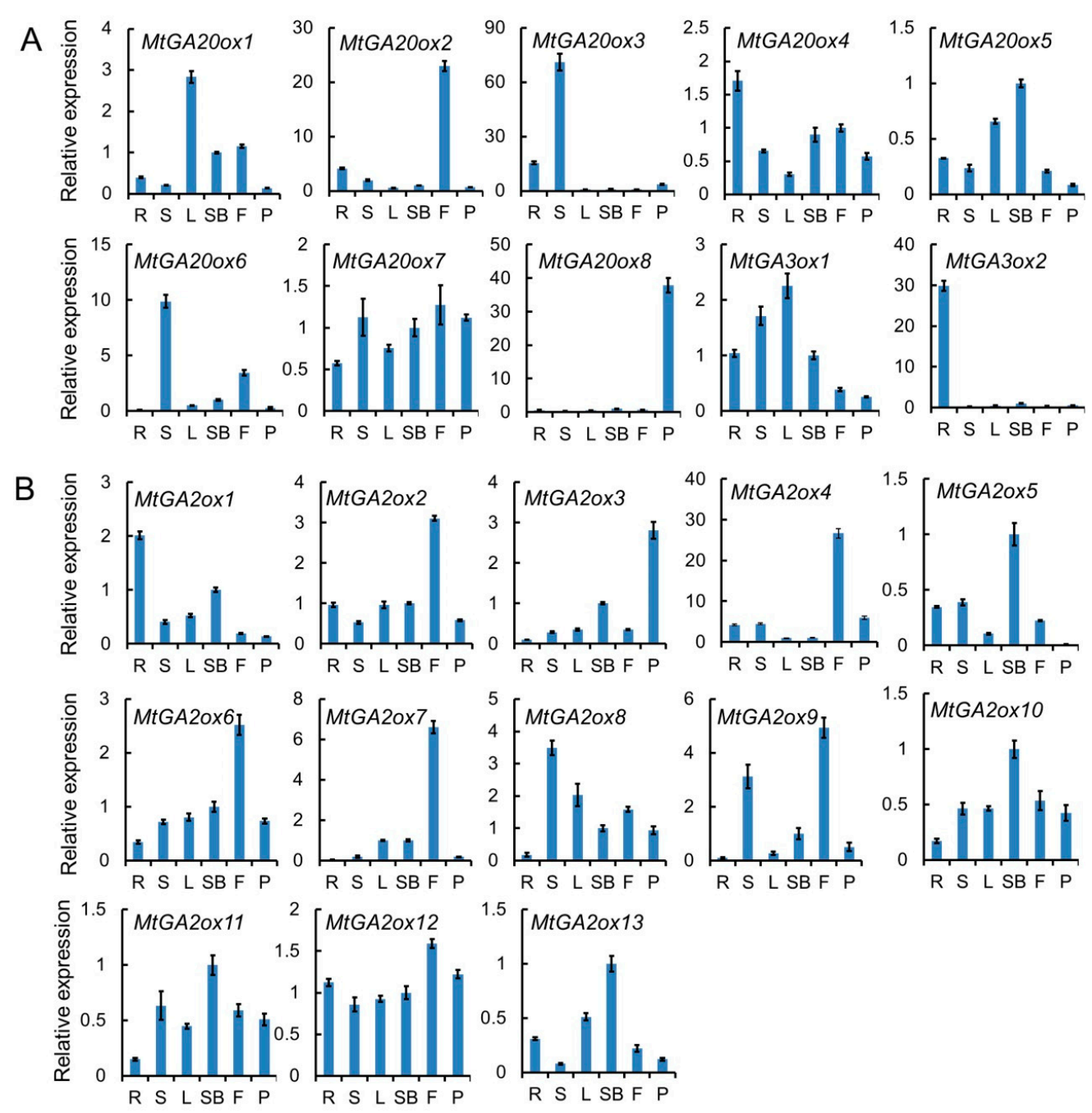

Figure 3. The expression patterns of MtGA20ox, MtGA3ox, and MtGA2ox genes in M. truncatula. (A) Expression analysis of gibberellin biosynthesis genes $M t G A 20 o x$ and $M t G A 3 o x$ in different tissues. (B) Expression analysis of gibberellin deactivation genes $M t G A 2 o x$ in different tissues. R, roots; S, stems; L, leaves; SB, shoot buds; F, flowers; P, pods. The level of expression was normalized to M. truncatula UBI gene. Error bars represent SD for three biological replicates. 


\subsection{Identification of GA Receptor MtGID1 and MtDELLA Genes in M. truncatula}

When GA is present, the GID1 receptors bind to GA and this binding promotes the interaction of GID1 with DELLA proteins, which are degraded in the 26S proteasome later (Figure S6). To identify MtGID1 and MtDELLA proteins in M. truncatula, BLASTP searches were performed using 3 AtGID1 and 5 AtDELLA sequences. A total of three GA receptor proteins, MtGID1A, MtGID1B, and MtGID1C, and 3 MtDELLA proteins, MtDELLA1, MtDELLA2, and MtDELLA3, were identified (Table S2; Figure 4A; Figures S7 and S8;). Gene structure analysis showed that the MtDELLA genes had the same exon-intron organization with no intron, whereas the intron of MtGID1 genes ranged from 1 to 2 (Figure 4B).

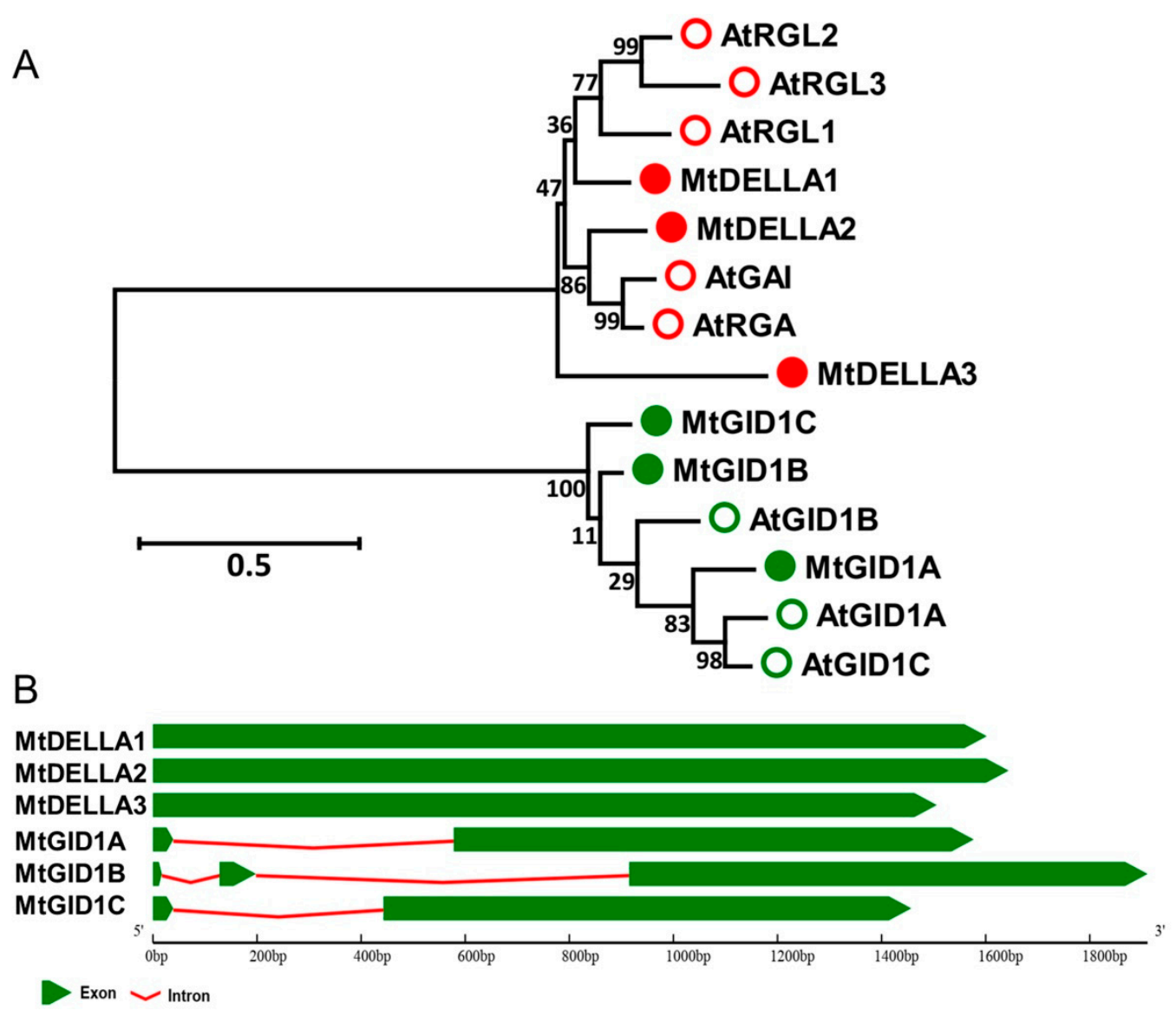

Figure 4. Phylogenetic tree analysis and exon-intron structures of the DELLA and GID1 gene family. (A) Phylogenetic analysis of DELLA and GID1 proteins from A. thaliana and M. truncatula. The tree is generated with MEGA 7.0 software using the Neighbor-Joining (NJ) method. The bootstrap analysis was conducted with 1000 iterations. The values on the phylogenetic tree represent the result of bootstrap analysis conducted with 1000 iterations. The scale bar indicates that the sequence divergence is 0.05 per unit bar, which represent $5 \%$ substitutions per nucleotide position. The empty and full circles in red color represent $A$. thaliana and $M$. truncatula DELLA proteins and the empty and full circles in green color represent $A$. thaliana and $M$. truncatula GID1 receptor proteins (B) The gene structures of the $M t D E L L A s$ and MtGID1s. Exons are represented by green boxes; introns are shown as red lines.

\subsection{Expression Patterns of MtGID1 and MtDELLA Genes}

To gain better insights into the potential functions of MtGID1 and MtDELLA genes, their expression patterns were analyzed (Figure 5; Figures S9 and S10). The qRT-PCR results indicated that MtDELLA1 and MtDELLA2 had similar expression patterns and were detected at low levels in all tissues, indicating that MtDELLA1 and MtDELLA2 are involved in many aspects of growth and development. Moreover, 
$M t D E L L A 3$ had higher expression level in pods compared to that in root and stems (Figure 5A), implying that MtDELLA3 may play more important roles in pod development. The expression levels of $M t G I D 1 B$ and $M t G I D 1 C$ were higher in root than those in other tissues (Figure $5 \mathrm{~B}$ ), demonstrating that $M t G I D 1 B$ and MtGID1C may play a significant role in root development than other tissues. However, $M t G I D 1 A$ was widely expressed in all tissues tested (Figure 5B), although at low level, suggesting that it may be involved in multiple developmental processes.
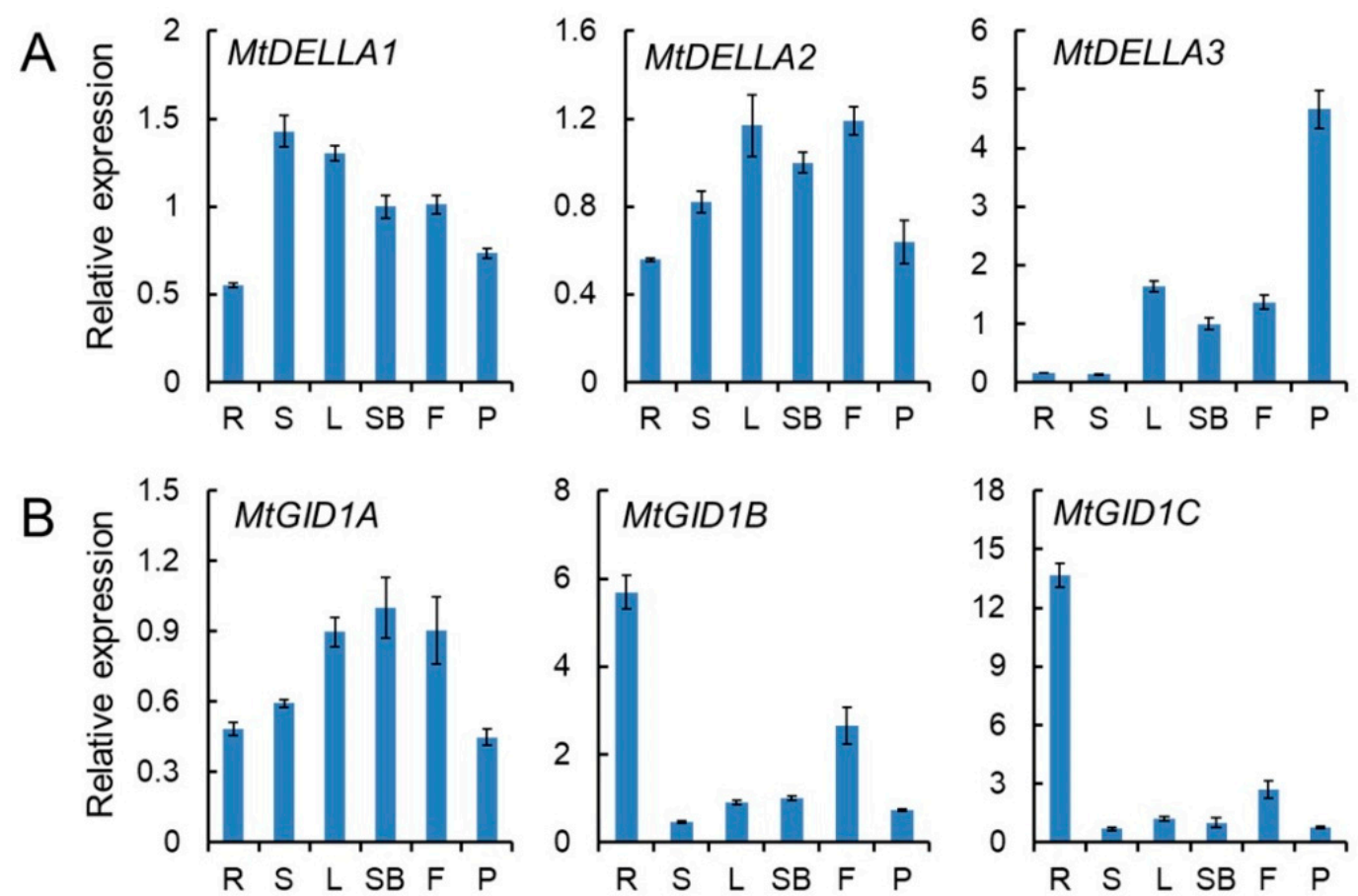

Figure 5. Expression patterns of $M t D E L L A(\mathbf{A})$ and $M t G I D 1$ (B) genes in six different tissues. R, roots; S, stems; L, leaves; SB, shoot buds; F, flowers; P, pods. The level of expression was normalized to M. truncatula UBI gene. Error bars represent SD for three biological replicates.

\subsection{The GA Receptors, MtGID1s, Were Able to Interact with MtDELLA Proteins}

In DELLA protein, two important and conserved motifs, DELLA and VHYNP, are involved in the interaction with GID1 proteins [55,56]. In addition, the SUMO-Interaction Motif (SIM), which is important for the recognition of SUMOylated DELLA proteins, is also highly conserved between GID1s [57,58]. Multiple sequences alignment showed that the three MtDELLA proteins had the typical DELLA and VHYNP domains (Figure 6A; Figure S11) and the three MtGID1 receptors had the conserved DELLA interaction SIM motif (Figure 6B; Figure S11). To verify that the MtDELLA and MtGID1 proteins are functional GA signaling components, we assessed the interaction between MtDELLAs and MtGID1s using the yeast two-hybrid system (Figure 7). We also performed the interaction tests between MtDELLAs and MtGID1s in opposite orientation and obtained the same results (Figure S12). MtGID1s interacted with MtDELLA1 and MtDELLA2 in yeast cells in the presence of $\mathrm{GA}_{3}$, but not in $\mathrm{GA}_{3}$-free medium, while MtGID1s could not interact with MtDELLA3. These results indicate that all three MtGID1s are functional GA receptors and MtDELLA1 and MtDELLA2 may play more important roles in the GA pathway. 
A AtGAl DELLAVLGYKVRSSEMADVAQKLEQLEVMMSNVQ ....... EDDLSQLATETVHYNP AtRGA DELLAVLGYKVRSSEMAEVALKLEQLETMMSNVQ ........ EDGLSHLATDTVHYNP ATRGL1 DELLVVLGYKVRSSDMADVAHKLEQLEMVLG . . . . . . . . . DGI SNL SDETVHYNP AtRGL2 DELLAVLGYKVRSSEMAEVAQKLEQLEMVLSNDD . . . . . . VG-STVLNDSVHYNP ATRGL3 DEFLAVLGYKVRSSDMADVAQKLEQLEMVLSNDI . . . . . . ASSSNAFNDTVHYNP MIDELLA1 DELLAALGYKVRSSDMADVAQKLEQLEMVMGSAQ . . . . . . EEG INHLSSDTVHYDP MIDELLA2 DELLAVVGYKVKS SDMAEVAQKLEQLEQAMMGNN - - FHDHDESTIAQHLSNDTVHYNP MTDELLA3 DGLLANVGYKVRSSELHQVAQNLERLESA IVNSS .......... SDISQFASDTVHYDP

B AtGID1A MAASDEVNLI ESRTVVPLNTWVLI SNFKVAYNILRRPDGTFNRHLAEYLDRKVTANANP ATGID1B MAGGNEVNLNECKRIVPLNTWVL I SNFKLAYKVLRRPDGSFNRDLAEFLDRKVPANSFP AtGID1C MAGSEEVNL I ESKTVVPLNTWVL I SNFKLAYNLLRRPDGTFNRHLAEFLDRKVPANANP MIGID1A MAGSNQLNPNDSKMVVPLNMWVL I SNFKLAYNLLRRPDGTFNRDLAEFLDRKVPANANP MIGID1B MAGSNEVNLNESKSVVPLNTWVL I SNFKL AYNLLRRADGTFNREL AEFLDRKVPANTIP MEIDIC MTGTNEVNLSESRSVVPLNTYVLI SNFKLAYNLLRRADGTFNRDLAEFLDRKVPANAIP

Figure 6. Multiple Sequence alignment of DELLA, VHYNP and SIM domains in DELLA and GID1 proteins. (A) DELLA and VHYNP domain sequences alignment for DELLA homologues in A. thaliana and M. truncatula. Black lines indicate the DELLA (left) and VHYNP (right) domain. (B) SUMO-Interaction Motif (SIM) sequences alignment for GID1 homologues in A. thaliana and M. truncatula. The black line indicates the SIM motif (W[V/I]LI). Amino acids that are conserved throughout are shaded in different colors.

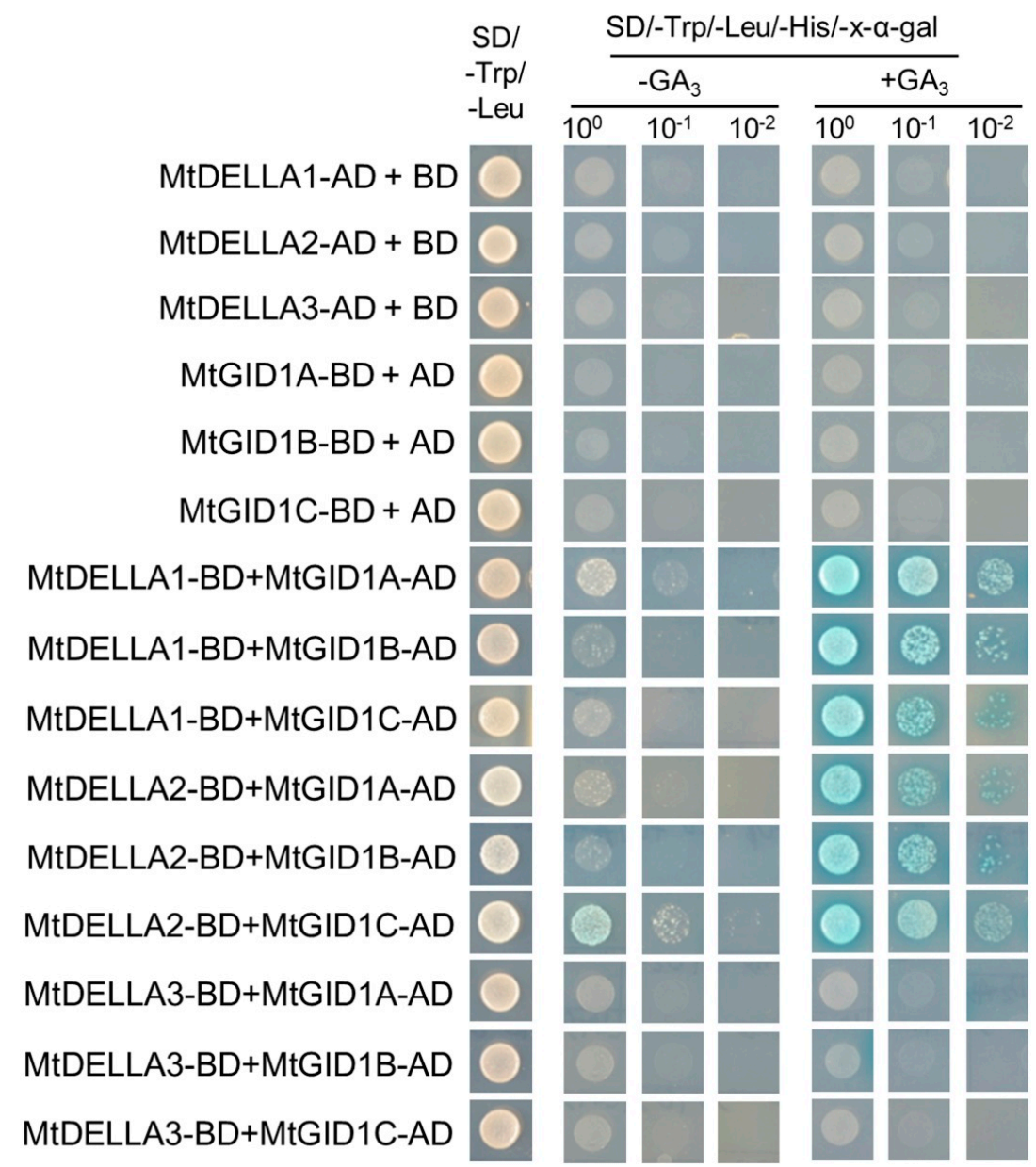

Figure 7. Interaction tests between MtDELLA and MtGID1 proteins in the yeast two-hybrid system. Yeast transformants are spotted onto the control medium (SD/-Leu/-Trp) and selective medium (SD/-Leu/-Trp/-His/-Ade). The initial concentration of the yeast cells spots on SD/-Trp/-Leu (panel 1) and SD/-Trp/-Leu/-His/-Ade medium (panels 2 and 5) were OD600 $=0.2$. Then, the yeast cells were diluted 10 and 100 times and were plated onto selective medium (panels 3, 4, 6 and 7) containing $20 \mu \mathrm{g} / \mathrm{mL} \mathrm{X- \alpha -gal} \mathrm{with} \mathrm{or} \mathrm{without} \mathrm{GA}_{3}\left(10^{-5} \mathrm{M}\right)$. 


\subsection{The Transcript Level of MtGAoxs Is Regulated by a Feedback Mechanism}

Previous studies indicated that feedback regulation controls the concentrations of active GAs in higher plants and the gibberellin metabolism genes also respond to exogenous GA treatment $[59,60]$. To investigate whether the expression level of MtGA20ox, MtGA3ox, and MtGA2ox are regulated by a feedback mechanism, leaves were treated with $\mathrm{GA}_{3}$ and gibberellin inhibitor PAC, and the transcriptional changes were analyzed using qRT-PCR (Figure 8). qRT-PCR results showed that the transcript levels of $M t G A 20 o x 1, M t G A 20 o x 2, M t G A 20 o x 6$ and $M t G A 3 o x 1$ were downregulated after $24 \mathrm{~h}$ treatment of $50 \mu \mathrm{M}$ and $100 \mu \mathrm{M} \mathrm{GA}_{3}$ (Figure $8 \mathrm{~A}$ ), indicating that these genes respond quickly to exogenous $\mathrm{GA}_{3}$ treatment. On the opposite, the expressions of MtGA20ox3, MtGA20ox4, MtGA20ox5, $M t G A 20 o x 8$, and $M t G A 30 x 2$ were upregulated when treated with $100 \mu \mathrm{M} \mathrm{GA}_{3}$ (Figure 8A), implying that upregulation of these genes may compensate for the downregulation of MtGA20ox1, MtGA20ox2, $M t G A 200 x 6$, and $M t G A 30 x 1$ genes to balance the GA level in plant. However, the transcript levels of $M t G A 20 o x 5, M t G A 20 o x 8, M t G A 3 o x 1$, and MtGA3ox2 were upregulated when treated with $100 \mu \mathrm{M}$ PAC (Figure 8A), indicating that these genes may play important roles in GA synthesis. Meanwhile, GA treatment promoted the transcription of some $M t G A 2 o x$ genes, such as $M t G A 2 o x 2, M t G A 20 \times 3$, $M t G A 20 x 4, M t G A 20 x 5, M t G A 2 o x 6, M t G A 20 x 7, M t G A 2 o x 10$, and MtGA2ox13 (Figure 8B), demonstrating that these genes may have key roles in GA inactivation. After treatment with PAC, the downregulated genes were MtGA2ox1, MtGA2ox2, MtGA2ox4, MtGA2ox10, MtGA2ox11, and MtGA2ox12 (Figure 8B). These data showed that $M t G A 20$ oxs are responsible for the regulation of bioactive GA synthesis and $M t G A 20 x s$ regulate the degradation of GA.
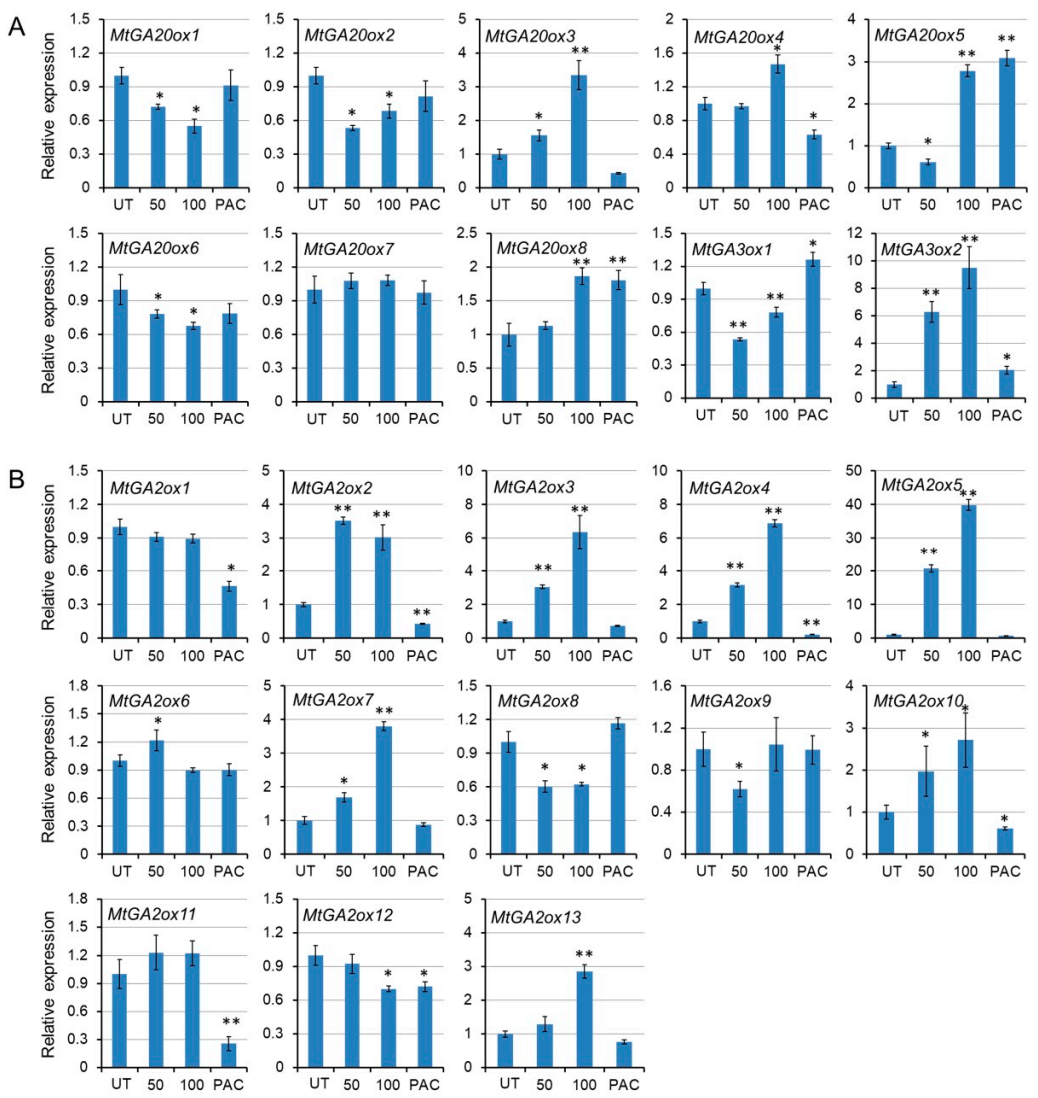

Figure 8. The transcript levels of $M t G A 20 o x, M t G A 3 o x$, and $M t G A 20 x$ are regulated by gibberellin 3 $\left(\mathrm{GA}_{3}\right)$ and its inhibitor paclobutrazol (PAC) through a feedback mechanism. (A) The transcript levels of $M t G A 200 x$ and $M t G A 30 x$ are regulated by $\mathrm{GA}_{3}$ and PAC. (B) The transcript levels of MtGA2ox are regulated by $\mathrm{GA}_{3}$ and PAC. Leaves are treated with 50 and $100 \mu \mathrm{M} \mathrm{GA}$, and $10 \mu \mathrm{M}$ PAC. Gene expression is normalized to the control untreated (UT) expression level. Data represent the average of three independent experiments \pm SD. ${ }^{*} p<0.05,{ }^{* *} p<0.01$. 


\subsection{GA Has a Positive Effect on Growth and Biomass of M. truncatula and Alfalfa}

To further investigate the in vivo function of GA, wild-type Medicago plants were transformed with 35S:MtGA20OX1 (Figure S13A). Fourteen regeneration lines were obtained and eleven were positive by PCR analysis (Figure S13B). Quantitative real-time PCR data showed that transcripts of $M t G A 20 O X 1$ were significantly increased in these transgenic plants, and the overexpression lines (OE) 3 and 9 were selected for further analysis (Figure S12C). To evaluate the effects of MtGA20OX1 expression on Medicago development, the following traits were measured: leaf size, plant height, and biomass. Under the same growth conditions, the MtGA20OX1 overexpression lines exhibited larger cotyledon and leaf size, compared with those of the controls (Figure 9A-C). Moreover, the plant height of MtGA20OX1 transgenic lines was measured. The MtGA20OX1 overexpression lines showed an increase in plant height, compared with that of the controls (Figure 9D-E). Then, we evaluated total above-ground biomass yield of 10 weeks old wild-type and MtGA20OX1 transgenic plants. The average fresh and dry weight of the MtGA20OX1 transgenic plants had a significant increase in total biomass, compared with those of wild-type (Figure $9 \mathrm{~F}-\mathrm{G}$ ).
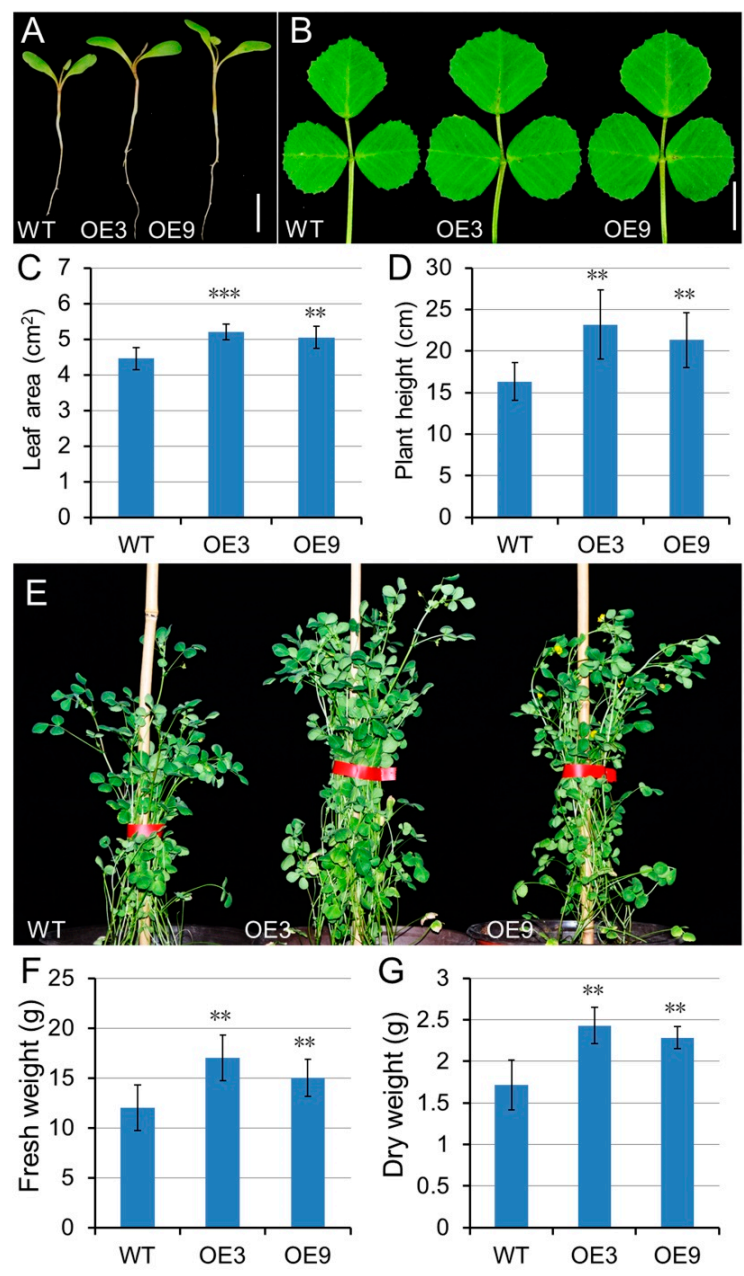

Figure 9. Overexpression of $M t G A 20 O X 1$ promoted biomass production. (A,B) The cotyledeon and leaf phenotypes of the wild type and MtGA20OX1 transgenic lines. (C) Measurements of the blade area of compound leaves on the fifth node of 4-week-old WT and MtGA20OX1 transgenic plants (means \pm SD; $n=5$ ). (D) The plant height of MtGA20OX1 transgenic and wild type plants within 50 days (means $\pm \mathrm{SD} ; n=13$ ). (E) Morphology of wild-type (WT) and MtGA20OX1 overexpressing M. truncatula plants. (F,G) The fresh and dry weight of developing wild type and MtGA20OX1 transgenic plants (means $\pm \mathrm{SD} ; n=10$ ). Bars $=1 \mathrm{~cm}$ in A and B. ${ }^{* *} p<0.01,{ }^{* * *} p<0.001$. 


\subsection{Transcription Analysis of Cell Development Related Genes in Transgenic Lines}

To explore the molecular mechanism of the increasing biomass of MtGA20OX1-overexpressing plants, the expression level of cell division related genes were examined. The results showed that the transcript levels of $M t C Y C B 1.1, M t C Y C B 1.2$, and MtCYCD2.1 were up-regulated in $M t G A 20 O X 1$-overexpressing plants (Figure 10A-C), whereas MtKRP1, MtKRP2, and MtKRP3 genes encoding the cyclin-dependent kinase inhibitor, were down-regulated (Figure 10D-F). These results suggest that overexpression of MtGA20OX1 might promote plant growth by controlling cell division.

A

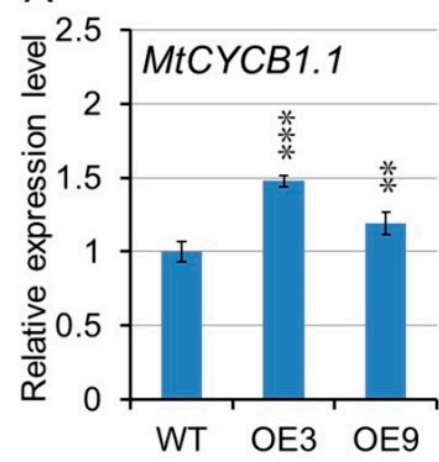

D

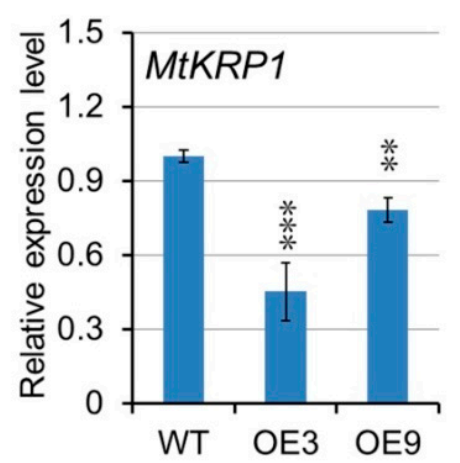

B

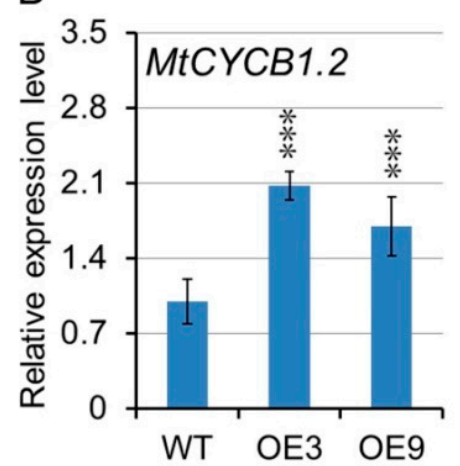

E

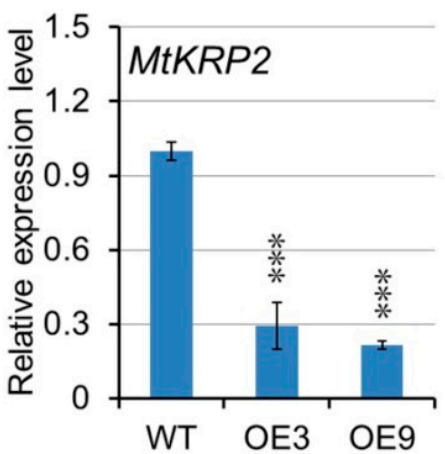

C

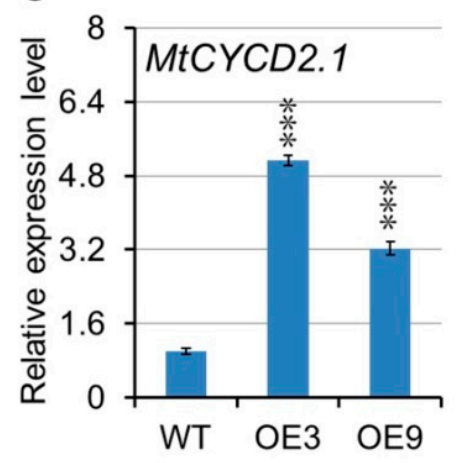

$\mathrm{F}$

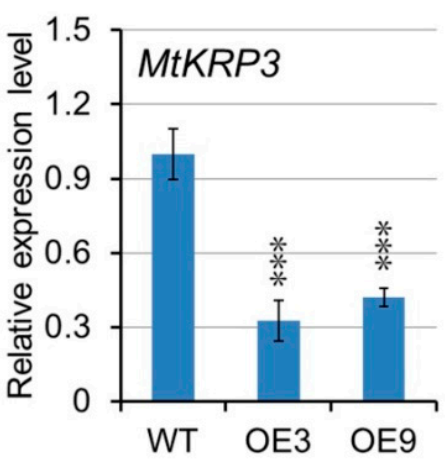

Figure 10. Expression analysis of cell development related genes in wild-type and MtGA20OX1 transgenic lines. (A-C) The expression of cyclindependent protein kinase genes, MtCYCB1.1, $M t C Y C B 1.2$, and MtCYCD2.1. (D-F) The expression of MtKRP1, MtKRP2, and MtKRP3 genes. ${ }^{* *} p<0.01,{ }^{* * *} p<0.001$.

\section{Discussion}

Gibberellins (GAs) play a crucial role in regulating plant growth and development $[9,61-63]$. However, to date, little was known about the gene families involved in GA biosynthesis, catabolism, and signaling in M. truncatula. In this study, 8 MtGA20ox, 2 MtGA3ox, 13 MtGA2ox, 3 MtGID1, and $3 \mathrm{MtDELLA}$ genes were identified in M. truncatula through bioinformatics analysis. Moreover, we evaluated the developmental responses of Medicago and alfalfa to $\mathrm{GA}_{3}$ and PAC treatment.

The MtGAox genes were distributed among chromosomes with different densities. The number of MtGA20ox and MtGA2ox genes was 1.75-fold larger than that in Arabidopsis, suggesting that the $M t G A 20 o x$ and $M t G A 2 o x$ ancestor may have experienced gene expansion and there may be gene redundancies in functions $[14,15,64,65]$. However, the GA3ox subfamily included 4 AtGA3ox and 2 MtGA3ox proteins, suggesting that the MtGA3ox family have experienced gene loss during evolution compared with that of Arabidopsis. Gene structure analysis indicated that the exon-intron organization of GAox members in the same group were highly conserved in Medicago, Arabidopsis, and rice [66].

The patterns of gene structure diversity and motif composition can provide significant evidence of the evolutionary relationships of multi-gene families [67,68]. Gene structure and motif analysis 
revealed that the most closely related members of the MtGAoxs family showed similar exon-intron organization and motif distribution, implying that they is functional conservation in the gibberellin metabolic pathway. Specific motifs in amino acid sequences are important regions for their functions. All of the MtGAox proteins contained the conserved 2OG-FeII_Oxy and DIOX_N domains.

Gene expression patterns analysis can be used to predict the molecular functions of genes in the development of different organs or tissues. In our study, the GA biosynthesis genes, MtGA3ox2, $M t G A 200 \times 3, M t G A 200 \times 2$, and $M t G A 20 o x 8$, were specifically expressed in root, stem, flower, and pod. Further, additional studies are needed to explore the function of these genes in specific organs in more detail. However, the GA deactivation genes were more widely expressed in all organs, demonstrating that they may play critical roles in processes involved in growth and development of M. truncatula. MtDELLA1, MtDELLA2, and MtGID1A were highly expressed in all organs, indicating that these genes might play more important roles in GA signaling transduction in $M$. truncatula.

Previous studies have indicated that the feedback regulation mechanism controls the concentration of active GAs in higher plants $[69,70]$. In most plants, GA20ox and GA3ox genes were involved in the final steps of GA biosynthesis and the expression of GA20ox and GA30x was downregulated by exogenous GA treatment $[59,70]$. In contrast, the transcript of $G A 20 x$ genes was upregulated by GA treatment [65]. In Vitis Vinifera L. and Camellia sinensis (L.) O. Kuntze, the expression levels of $V v G A 20 o x 1, V v G A 20 o x 2, C_{s} G A 20 o x 2$, and $C_{S} G A 20 o x 3$ were downregulated under $\mathrm{GA}_{3}$ treatment and the same was observed for the expression of MtGA20ox1, MtGA20ox2, and MtGA3ox1 in M. truncatula. In addition, most of the genes encoding MtGA2ox proteins were upregulated by $\mathrm{GA}_{3}$ treatment and only two genes, $M t G A 20 \times 2$ and $M t G A 20 \times 4$, can respond to both $\mathrm{GA}_{3}$ and PAC treatments. Our results demonstrated that the feedback regulation of GA in M. truncatula is similar to that of previous studies, indicating that the feedback regulation mechanism is conserved and the $M t G A o x$ genes are functional components of the GA metabolic pathway [69].

The GID receptors and DELLA proteins are master components of GA signaling [29,31,71]. Phylogenetic analyses showed that the Medicago genome contains three GA receptors (MtGID1A, MtGID1B, and MtGID1C) and three DELLA proteins (MtDELLA1, MtDELLA2, and MtDELLA3). The number of MtGID1s is identical to those in Arabidopsis and tomato, indicating that the evolutionary mechanisms of MtGID1s are more conservative than MtDELLAs [32,35,57]. In rice, GID1 interacts with DELLA protein SLR1 in a GA-dependent manner in yeast cells [22]. Moreover, AtGID1s can interact with AtDELLA proteins yeast cells in the presence of $\mathrm{GA}_{4}$ [33]. In M. truncatula, MtGID1s physically interacts with MtDELLA1 and MtDELLA2 in the yeast two-hybrid system in the presence of $\mathrm{GA}_{3}$. Although MtDELLA2 and MtGID1C had a weak interaction at the initial concentration $\left(10^{\circ}\right)$ in the absence of $\mathrm{GA}_{3}$, further dilution and configuration tests showed that the interaction between MtDELLA2 and MtGID1C is mainly in a GA-dependent manner. These results demonstrate that MtGID1s, MtDELLA1, and MtDELLA2 are functional GA signal components. However, MtGID1s and MtDELLA3 cannot interact with or without $\mathrm{GA}_{3}$. Several studies have elucidated that GA regulation of nodulation depends on DELLA proteins in legumes [72-74]. It is likely that MtDELLA3 may participate in symbiotic nodulation in a GA-independent manner.

In tomato plants with compound leaves, exogenous GA application resulted in less complex leaves with smooth leaf margins [47,75]. However, leaf complexity is not suppressed by GA treatment in $M$. truncatula and alfalfa, whose leaves consist of three leaflets, indicating that the effects of GA on leaf complexity may be species-dependent. Furthermore, GA promotes stem elongation in M. truncatula and this function is conserved in multiple species [54,76-80]. It has long been known that GA controls plant growth and development by regulating cell expansion, cell elongation, and cell division. In this study, the MtGA20OX1-overexpressing plants showed increased leaf size compared to the wild-type. The cyclin-dependent protein kinase genes were up-regulated in transgenic lines, while, the inhibitor genes were down-regulated. In the future, genetic improvement of alfalfa may be achieved by enhancing GA biosynthesis or signals, such as ectopic expression of GA20ox and receptors GID1s or mutation in GA2oxs and DELLA. 


\section{Materials and Methods}

\subsection{Plant Materials and Treatments}

M. truncatula wild-type (R108 ecotype) and 35S:MtGA20OX1 seeds were scarified and germinated at $4{ }^{\circ} \mathrm{C}$ for one week. The geminated seeds were transferred to nursery seedling plate $(4 \times 4 \times 4 \mathrm{~cm}$ Length, Width, Height) for 2 weeks in a light incubator (day: $24{ }^{\circ} \mathrm{C}, 16 \mathrm{~h}$; night: $22{ }^{\circ} \mathrm{C}, 8 \mathrm{~h}$; relative humidity: $75 \%)$. Then, the seedlings were transferred to pots $(15 \times 15 \times 25 \mathrm{~cm}$ Length, Width, Height) with soil mix (soil: vermiculite $=3: 1$ ) and grown in a greenhouse at $24{ }^{\circ} \mathrm{C}$ (day) $/ 22{ }^{\circ} \mathrm{C}$ (night) with $16 \mathrm{~h}$ (day)/8 h (night) photoperiod, and relative humidity at 70 to $80 \%$. For GA and paclobutrazol (PAC) treatment, $\mathrm{GA}_{3}$ and PAC were dissolved in ethanol at a stock concentration of $100 \mathrm{mM}$ and $10 \mathrm{mM}$. One-month-old wild-type plants grown in pots were treatment with $\mathrm{GA}_{3}$ and PAC at the final concentration of $100 \mu \mathrm{M}$ and $10 \mu \mathrm{M}$ for four weeks. Distilled water was used as a control. Each treatment was performed with 20 biological triplicates.

\subsection{Identification and Phylogenetic Analysis of GA20ox, GA3ox, GA2ox, GID, and DELLA Genes in M. truncatula}

To identify the GA metabolism and signaling genes in M. truncatula genome, we used 5 AtGA20ox, 4 AtGA3ox, 7 AtGA2ox, 3 AtGID1, and 5 AtDELLA protein sequences to BLAST the Medicago truncatula genome sequence (www.medicagogenome.org/). The Arabidopsis GA metabolism and signaling genes were obtained from TAIR (www.arabidopsis.org/). Totally, 8 MtGA20ox, 2 MtGA3ox, 13 MtGA2ox, $3 \mathrm{MtGID1}$, and $3 \mathrm{MtDELLA}$ genes were identified in $M$. truncatula genome using blast with an E-value $<1 \times 10^{-4}$. The protein sequences of these genes were listed in Table S4.

Multiple protein sequences alignment was performed using Jalview 2.10.5 software (www.jalview. org/). The phylogenetic tree of DELLA and GID1 proteins from A. thaliana and M.truncatula was constructed by MEGA 7.0 using the Neighbor-Joining (NJ) method with the following parameters: Poisson correction, pair-wise deletion and bootstrap values in percentages with 1000 replicates. The phylogenetic tree of GAoxs proteins from A. thaliana and M.truncatula was constructed on iTOLv5 (Interactive Tree of Life; https://itol.embl.de/) online website.

\subsection{Chromosome Location, Gene Structure, and Motif Detection}

The information, including chromosome length, gene location, and gene length, of MtGA20ox, $M t G A 3 o x$, and MtGA2ox genes on the chromosome were obtained from the $M$. truncatula genome database. MapGene (http://mg2c.iask.in/mg2c_v2.1/) was used to visualize the chromosomal distribution of these genes in $M$. truncatula genome.

The exon-intron structures of the MtGA20ox, MtGA3ox, MtGA2ox, MtGID1, and MtDELLA genes were drawn using the online GSDS 2.0 website (http://gsds.cbi.pku.edu.cn/) by comparing the coding sequences with their corresponding genomic sequences. The conserved protein motifs were analyzed using the MEME online tool (http://meme-suite.org/) with the following parameters: maximum number of motifs of 20 and the optimum width from 6 to 200 residues.

\subsection{RNA Extraction and $q R T-P C R$}

To detect the relative expression levels of $M t G A 20 o x, M t G A 3 o x, M t G A 2 o x, M t G I D 1$, and MtDELLA genes in root, shoot, leaf, flower, stem, and pod, total RNA was extracted from these tissues on two-month-old wild-type plants. To detect the effects of $\mathrm{GA}_{3}$ and PAC on the expression of MtGA20ox, $M t G A 3 o x$, and MtGA2ox, total RNA of leaves was extracted from plants after $24 \mathrm{~h} \mathrm{GA} 3$ and PAC treatment. To detect the relative expression levels of $M t G A 20 o x 1, M t C Y C B, M t C Y C D$, and $M t K P R$, total RNA of leaves was extracted from two-month-old wild-type and overexpression plants.

Total RNA was extracted using a Plant RNA Kit (TransGene Biotech, Beijing, China) following the manufacturer's instructions. The concentration and quality of the extracted RNA were evaluated using Nanodrop 2000 Spectrophotometer (Thermo Scientific, USA). Reverse transcription of RNA to cDNA 
was performed with $1 \mu \mathrm{g}$ total RNA using an iScript cDNA Synthesis Kit (Bio-Rad, Richmond, CA, USA). qRT-PCR was carried out in triplicate for each sample on a CFX Connect ${ }^{\mathrm{TM}}$ Detection System (Bio-Rad, Richmond, CA, USA) using TaKaRa SYBR Premix Kit (TaKaRa, Japan). MtUBI gene was used as the internal reference gene. The relative expression levels of the genes were calculated using the $2^{-\triangle \Delta C T}$ method. Primer sequences used for qRT-PCR analysis were listed in Table S3.

\subsection{Vector Construction and Plant Transformation}

To obtain the MtGA20OX1 overexpression construction, the 1149 bp CDS sequence was amplified using primer pair MtGA20OX1-F/MtGA20OX1-R. The MtGA20OX1 CDS sequence was transferred into the pB7WG2D vector by Gateway LR reaction (Invitrogen, Carlsbad, CA, USA). Then 35S:MtGA20OX1 destination construct was introduced into Agrobacterium strain EHA105. For stable transformation, leaves of wild-type were transformed with EHA105 strain containing the 35S:MtGA20OX1 vector. Primers used are listed in Table S3.

\subsection{Yeast Two-Hybrid}

The yeast two-hybrid assay was performed using the Gold System (Clontech, Mountain View, CA, USA). The coding sequence of MtDELLA1, MtDELLA2, and MtDELLA3 were cloned into the pGADT7 and pGBKT7 vectors, and the coding sequences of MtGID1A, MtGID1B, and MtGID1C were cloned into the pGADT7 and pGBKT7 vectors using the Gateway system. The bait and prey plasmids were co-transformed into yeast strain AH109. For the auxotrophic assay, yeast colonies were inoculated onto SD/-Trp/-Leu and SD/-Trp/-Leu/-His/-Ade plates with or without $10^{-5} \mathrm{M} \mathrm{GA}_{3}$ and incubated in the dark at $28^{\circ} \mathrm{C}$ for 3 days. The initial concentration of the yeast cells spots on both SD/-Trp/-Leu and $\mathrm{SD} /$-Trp/-Leu/-His/-Ade plates were OD600 $=0.2$. Then, yeast cells were diluted 10 and 100 times and spotted on SD/-Trp/-Leu/-His/-Ade selective media for detail interaction test analysis. All primers used are listed in Table S3.

\subsection{Statistical Analysis}

Statistical analysis was performed using the SPSS 22.0 statistical software (International Business Machines Corporation, Amonk City, NY, USA). The data relating to expression level and size were subjected to one-way ANOVA of variance followed by a comparison of the means according to a significant difference tested at $p<0.05$. The data are expressed as the mean $\pm \mathrm{SE}$.

Supplementary Materials: Supplementary Materials can be found at http://www.mdpi.com/1422-0067/21/19/ 7180/s1.

Author Contributions: Conceptualization, H.W.; investigation, H.J.; methodology, Y.X.; resources, Y.W.; software, L.Z., X.Y. and F.K.; supervision, C.Z. and L.H.; writing-review and editing, H.W. and L.H. All authors have read and agreed to the published version of the manuscript.

Funding: This work was supported by China Postdoctoral Science Foundation (2019M662836) and Natural Science Foundation of Shandong Province (ZR2018ZC0334 and ZR2019MC013).

Acknowledgments: We would like to thank Haiyan Yu from the State Key Laboratory of Microbial Technology of Shandong University for help and guidance in microscope.

Conflicts of Interest: The authors declare no conflict of interest.

\section{References}

1. Yamaguchi, S. Gibberellin Metabolism and its Regulation. Annu. Rev. Plant Biol. 2008, 59, 225-251. [CrossRef]

2. Sun, T.-P.; Gubler, F. MOLECULAR MECHANISM OF GIBBERELLIN SIGNALING IN PLANTS. Annu. Rev. Plant. Biol. 2004, 55, 197-223. [CrossRef] [PubMed]

3. Olszewski, N.; Sun, T.P.; Gubler, F. Gibberellin signaling: Biosynthesis, catabolism, and response pathways. Plant. Cell 2002, 14 (Suppl. 1), S61-S80. [CrossRef] [PubMed] 
4. McAdam, E.L.; Reid, J.B.; Foo, E. Gibberellins promote nodule organogenesis but inhibit the infection stages of nodulation. J. Exp. Bot. 2018, 69, 2117-2130. [CrossRef] [PubMed]

5. Hayashi, S.; Gresshoff, P.M.; Ferguson, B.J. Mechanistic action of gibberellins in legume nodulation. J. Integr. Plant Biol. 2014, 56, 971-978. [CrossRef] [PubMed]

6. Fonouni-Farde, C.; Kisiala, A.; Brault, M.; Emery, R.J.N.; Diet, A.; Frugier, F. DELLA1-Mediated Gibberellin Signaling Regulates Cytokinin-Dependent Symbiotic Nodulation. Plant Physiol. 2017, 175, 1795-1806. [CrossRef] [PubMed]

7. Ferguson, B.J.; Foo, E.; Ross, J.J.; Reid, J.B. Relationship between gibberellin, ethylene and nodulation in Pisum sativum. New Phytol. 2011, 189, 829-842. [CrossRef]

8. Maekawa, T.; Maekawa-Yoshikawa, M.; Takeda, N.; Imaizumi-Anraku, H.; Murooka, Y.; Hayashi, M. Gibberellin controls the nodulation signaling pathway in Lotus japonicus. Plant J. 2009, 58, 183-194. [CrossRef]

9. Sun, T.P. Gibberellin metabolism, perception and signaling pathways in Arabidopsis. Arab. Book 2008, 6, e0103. [CrossRef]

10. Salazar-Cerezo, S.; Martinez-Montiel, N.; Garcia-Sanchez, J.; Perez, Y.T.R.; Martinez-Contreras, R.D. Gibberellin biosynthesis and metabolism: A convergent route for plants, fungi and bacteria. Microbiol. Res. 2018, 208, 85-98. [CrossRef]

11. Ueguchi-Tanaka, M.; Nakajima, M.; Motoyuki, A.; Matsuoka, M. Gibberellin receptor and its role in gibberellin signaling in plants. Annu. Rev. Plant Biol. 2007, 58, 183-198. [CrossRef] [PubMed]

12. Vandenbussche, F.; Fierro, A.C.; Wiedemann, G.; Reski, R.; Van Der Straeten, D. Evolutionary conservation of plant gibberellin signalling pathway components. BMC Plant Biol. 2007, 7, 65. [CrossRef] [PubMed]

13. Sasaki, A.; Ashikari, M.; Ueguchi-Tanaka, M.; Itoh, H.; Nishimura, A.; Swapan, D.; Ishiyama, K.; Saito, T.; Kobayashi, M.; Khush, G.S.; et al. A mutant gibberellin-synthesis gene in rice. Nature 2002, 416, 701-702. [CrossRef] [PubMed]

14. Rieu, I.; Ruiz-Rivero, O.; Fernandez-Garcia, N.; Griffiths, J.; Powers, S.J.; Gong, F.; Linhartova, T.; Eriksson, S.; Nilsson, O.; Thomas, S.G.; et al. The gibberellin biosynthetic genes AtGA20ox1 and AtGA20ox2 act, partially redundantly, to promote growth and development throughout the Arabidopsis life cycle. Plant J. 2008, 53, 488-504. [CrossRef] [PubMed]

15. Mitchum, M.G.; Yamaguchi, S.; Hanada, A.; Kuwahara, A.; Yoshioka, Y.; Kato, T.; Tabata, S.; Kamiya, Y.; Sun, T.P. Distinct and overlapping roles of two gibberellin 3-oxidases in Arabidopsis development. Plant J. 2006, 45, 804-818. [CrossRef]

16. Hu, Y.X.; Tao, Y.B.; Xu, Z.F. Overexpression of Jatropha Gibberellin 2-oxidase 6 (JcGA2ox6) Induces Dwarfism and Smaller Leaves, Flowers and Fruits in Arabidopsis and Jatropha. Front. Plant Sci. 2017, 8, 2103. [CrossRef]

17. Yan, J.; Liao, X.; He, R.; Zhong, M.; Feng, P.; Li, X.; Tang, D.; Liu, X.; Zhao, X. Ectopic expression of GA 2-oxidase 6 from rapeseed (Brassica napus L.) causes dwarfism, late flowering and enhanced chlorophyll accumulation in Arabidopsis thaliana. Plant Physiol. Biochem. 2017, 111, 10-19. [CrossRef]

18. Eriksson, M.E.; Israelsson, M.; Olsson, O.; Moritz, T. Increased gibberellin biosynthesis in transgenic trees promotes growth, biomass production and xylem fiber length. Nat. Biotechnol. 2000, 18, 784-788. [CrossRef]

19. Hedden, P.; Kamiya, Y. GIBBERELLIN BIOSYNTHESIS: Enzymes, Genes and Their Regulation. Annu Rev. Plant Phys. 1997, 48, 431-460. [CrossRef]

20. Penfield, S.; Li, Y.; Gilday, A.D.; Graham, S.; Graham, I.A. Arabidopsis ABA INSENSITIVE4 regulates lipid mobilization in the embryo and reveals repression of seed germination by the endosperm. Plant Cell 2006, 18, 1887-1899. [CrossRef]

21. Oh, E.; Yamaguchi, S.; Hu, J.; Yusuke, J.; Jung, B.; Paik, I.; Lee, H.S.; Sun, T.P.; Kamiya, Y.; Choi, G. PIL5, a phytochrome-interacting bHLH protein, regulates gibberellin responsiveness by binding directly to the GAI and RGA promoters in Arabidopsis seeds. Plant Cell 2007, 19, 1192-1208. [CrossRef] [PubMed]

22. Ueguchi-Tanaka, M.; Ashikari, M.; Nakajima, M.; Itoh, H.; Katoh, E.; Kobayashi, M.; Chow, T.Y.; Hsing, Y.I.; Kitano, H.; Yamaguchi, I.; et al. GIBBERELLIN INSENSITIVE DWARF1 encodes a soluble receptor for gibberellin. Nature 2005, 437, 693-698. [CrossRef] [PubMed]

23. Livne, S.; Lor, V.S.; Nir, I.; Eliaz, N.; Aharoni, A.; Olszewski, N.E.; Eshed, Y.; Weiss, D. Uncovering DELLA-Independent Gibberellin Responses by Characterizing New Tomato procera Mutants. Plant Cell 2015, 27, 1579-1594. [CrossRef] 
24. Itoh, H.; Ueguchi-Tanaka, M.; Sato, Y.; Ashikari, M.; Matsuoka, M. The Gibberellin Signaling Pathway Is Regulated by the Appearance and Disappearance of SLENDER RICE1 in Nuclei. Plant Cell 2002, 14, 57-70. [CrossRef]

25. Harberd, N.P.; Belfield, E.; Yasumura, Y. The angiosperm gibberellin-GID1-DELLA growth regulatory mechanism: How an "inhibitor of an inhibitor" enables flexible response to fluctuating environments. Plant Cell 2009, 21, 1328-1339. [CrossRef] [PubMed]

26. Hauvermale, A.L.; Ariizumi, T.; Steber, C.M. Gibberellin signaling: A theme and variations on DELLA repression. Plant Physiol. 2012, 160, 83-92. [CrossRef]

27. Eckardt, N.A. GA perception and signal transduction: Molecular interactions of the GA receptor GID1 with GA and the DELLA protein SLR1 in rice. Plant Cell 2007, 19, 2095-2097. [CrossRef]

28. Jiang, C.; Fu, X. GA action: Turning on de-DELLA repressing signaling. Curr. Opin. Plant Biol. 2007, 10, 461-465. [CrossRef]

29. Sun, T.P. Gibberellin-GID1-DELLA: A pivotal regulatory module for plant growth and development. Plant Physiol. 2010, 154, 567-570. [CrossRef]

30. Ueguchi-Tanaka, M.; Nakajima, M.; Katoh, E.; Ohmiya, H.; Asano, K.; Saji, S.; Hongyu, X.; Ashikari, M.; Kitano, H.; Yamaguchi, I.; et al. Molecular interactions of a soluble gibberellin receptor, GID1, with a rice DELLA protein, SLR1, and gibberellin. Plant Cell 2007, 19, 2140-2155. [CrossRef]

31. Shimada, A.; Ueguchi-Tanaka, M.; Nakatsu, T.; Nakajima, M.; Naoe, Y.; Ohmiya, H.; Kato, H.; Matsuoka, M. Structural basis for gibberellin recognition by its receptor GID1. Nature 2008, 456, 520-523. [CrossRef] [PubMed]

32. Griffiths, J.; Murase, K.; Rieu, I.; Zentella, R.; Zhang, Z.L.; Powers, S.J.; Gong, F.; Phillips, A.L.; Hedden, P.; Sun, T.P.; et al. Genetic characterization and functional analysis of the GID1 gibberellin receptors in Arabidopsis. Plant Cell 2006, 18, 3399-3414. [CrossRef] [PubMed]

33. Nakajima, M.; Shimada, A.; Takashi, Y.; Kim, Y.C.; Park, S.H.; Ueguchi-Tanaka, M.; Suzuki, H.; Katoh, E.; Iuchi, S.; Kobayashi, M.; et al. Identification and characterization of Arabidopsis gibberellin receptors. Plant J. 2006, 46, 880-889. [CrossRef] [PubMed]

34. Iuchi, S.; Suzuki, H.; Kim, Y.C.; Iuchi, A.; Kuromori, T.; Ueguchi-Tanaka, M.; Asami, T.; Yamaguchi, I.; Matsuoka, M.; Kobayashi, M.; et al. Multiple loss-of-function of Arabidopsis gibberellin receptor AtGID1s completely shuts down a gibberellin signal. Plant J. 2007, 50, 958-966. [CrossRef]

35. Illouz-Eliaz, N.; Ramon, U.; Shohat, H.; Blum, S.; Livne, S.; Mendelson, D.; Weiss, D. Multiple Gibberellin Receptors Contribute to Phenotypic Stability under Changing Environments. Plant Cell 2019, 31, 1506-1519. [CrossRef]

36. Sun, T.P. The molecular mechanism and evolution of the GA-GID1-DELLA signaling module in plants. Curr. Biol. 2011, 21, R338-R345. [CrossRef]

37. McGinnis, K.M.; Thomas, S.G.; Soule, J.D.; Strader, L.C.; Zale, J.M.; Sun, T.P.; Steber, C.M. The Arabidopsis SLEEPY1 gene encodes a putative F-box subunit of an SCF E3 ubiquitin ligase. Plant Cell 2003, 15, 1120-1130. [CrossRef]

38. Sasaki, A.; Itoh, H.; Gomi, K.; Ueguchi-Tanaka, M.; Ishiyama, K.; Kobayashi, M.; Jeong, D.-H.; An, G.; Kitano, H.; Ashikari, M.; et al. Accumulation of Phosphorylated Repressor for Gibberellin Signaling in an F-box Mutant. Science 2003, 299, 1896-1898. [CrossRef]

39. Dill, A.; Thomas, S.G.; Hu, J.; Steber, C.M.; Sun, T.P. The Arabidopsis F-box protein SLEEPY1 targets gibberellin signaling repressors for gibberellin-induced degradation. Plant Cell 2004, 16, 1392-1405. [CrossRef]

40. Gomi, K.; Sasaki, A.; Itoh, H.; Ueguchi-Tanaka, M.; Ashikari, M.; Kitano, H.; Matsuoka, M. GID2, an F-box subunit of the SCF E3 complex, specifically interacts with phosphorylated SLR1 protein and regulates the gibberellin-dependent degradation of SLR1 in rice. Plant J. 2004, 37, 626-634. [CrossRef]

41. Marti, C.; Orzaez, D.; Ellul, P.; Moreno, V.; Carbonell, J.; Granell, A. Silencing of DELLA induces facultative parthenocarpy in tomato fruits. Plant J. 2007, 52, 865-876. [CrossRef] [PubMed]

42. Willige, B.C.; Ghosh, S.; Nill, C.; Zourelidou, M.; Dohmann, E.M.; Maier, A.; Schwechheimer, C. The DELLA domain of GA INSENSITIVE mediates the interaction with the GA INSENSITIVE DWARF1A gibberellin receptor of Arabidopsis. Plant Cell 2007, 19, 1209-1220. [CrossRef]

43. Bassel, G.W.; Mullen, R.T.; Bewley, J.D. Procera is a putative DELLA mutant in tomato (Solanum lycopersicum): Effects on the seed and vegetative plant. J. Exp. Bot. 2008, 59, 585-593. [CrossRef] [PubMed] 
44. Jasinski, S.; Tattersall, A.; Piazza, P.; Hay, A.; Martinez-Garcia, J.F.; Schmitz, G.; Theres, K.; McCormick, S.; Tsiantis, M. PROCERA encodes a DELLA protein that mediates control of dissected leaf form in tomato. Plant J. 2008, 56, 603-612. [CrossRef] [PubMed]

45. Peng, J.; Carol, P.; Richards, D.E.; King, K.E.; Cowling, R.J.; Murphy, G.P.; Harberd, N.P. The Arabidopsis GAI gene defines a signaling pathway that negatively regulates gibberellin responses. Gene Dev. 1997, 11, 3194-3205. [CrossRef]

46. Asano, K.; Hirano, K.; Ueguchi-Tanaka, M.; Angeles-Shim, R.B.; Komura, T.; Satoh, H.; Kitano, H.; Matsuoka, M.; Ashikari, M. Isolation and characterization of dominant dwarf mutants, Slr1-d, in rice. Mol. Genet. Genom. 2009, 281, 223-231. [CrossRef]

47. Fleishon, S.; Shani, E.; Ori, N.; Weiss, D. Negative reciprocal interactions between gibberellin and cytokinin in tomato. New Phytol. 2011, 190, 609-617. [CrossRef]

48. Dill, A.; Sun, T.-P. Synergistic Derepression of Gibberellin Signaling by Removing RGA and GAI Function in Arabidopsis thaliana. Genetics 2001, 159, 777.

49. Dill, A.; Jung, H.-S.; Sun, T.-P. The DELLA motif is essential for gibberellin-induced degradation of RGA. Proc. Natl. Acad. Sci. USA 2001, 98, 14162-14167. [CrossRef]

50. Pearce, S.; Saville, R.; Vaughan, S.P.; Chandler, P.M.; Wilhelm, E.P.; Sparks, C.A.; Al-Kaff, N.; Korolev, A.; Boulton, M.I.; Phillips, A.L.; et al. Molecular characterization of Rht-1 dwarfing genes in hexaploid wheat. Plant Physiol. 2011, 157, 1820-1831. [CrossRef]

51. Peng, J.; Richards, D.E.; Hartley, N.M.; Murphy, G.P.; Devos, K.M.; Flintham, J.E.; Beales, J.; Fish, L.J.; Worland, A.J.; Pelica, F.; et al. 'Green revolution' genes encode mutant gibberellin response modulators. Nature 1999, 400, 256-261. [CrossRef] [PubMed]

52. Biemelt, S.; Tschiersch, H.; Sonnewald, U. Impact of altered gibberellin metabolism on biomass accumulation, lignin biosynthesis, and photosynthesis in transgenic tobacco plants. Plant Physiol. 2004, 135, 254-265. [CrossRef] [PubMed]

53. Wang, X.; Li, J.; Ban, L.; Wu, Y.; Wu, X.; Wang, Y.; Wen, H.; Chapurin, V.; Dzyubenko, N.; Li, Z.; et al. Functional characterization of a gibberellin receptor and its application in alfalfa biomass improvement. Sci. Rep. 2017, 7, 41296. [CrossRef]

54. Do, P.T.; De Tar, J.R.; Lee, H.; Folta, M.K.; Zhang, Z.J. Expression of ZmGA20ox cDNA alters plant morphology and increases biomass production of switchgrass (Panicum virgatum L.). Plant Biotechnol. J. 2016, 14, 1532-1540. [CrossRef] [PubMed]

55. Daviere, J.M.; Achard, P. A Pivotal Role of DELLAs in Regulating Multiple Hormone Signals. Mol. Plant 2016, 9, 10-20. [CrossRef]

56. Locascio, A.; Blázquez, M.A.; Alabadí, D. Genomic Analysis of DELLA Protein Activity. Plant Cell Physiol. 2013, 54, 1229-1237. [CrossRef]

57. Gazara, R.K.; Moharana, K.C.; Bellieny-Rabelo, D.; Venancio, T.M. Expansion and diversification of the gibberellin receptor GIBBERELLIN INSENSITIVE DWARF1 (GID1) family in land plants. Plant Mol. Biol. 2018, 97, 435-449. [CrossRef]

58. Conti, L.; Nelis, S.; Zhang, C.; Woodcock, A.; Swarup, R.; Galbiati, M.; Tonelli, C.; Napier, R.; Hedden, P.; Bennett, M.; et al. Small Ubiquitin-like Modifier protein SUMO enables plants to control growth independently of the phytohormone gibberellin. Dev. Cell 2014, 28, 102-110. [CrossRef]

59. Hedden, P.; Phillips, A.L. Gibberellin metabolism: New insights revealed by the genes. Trends Plant Sci. 2000, 5, 523-530. [CrossRef]

60. Plackett, A.R.; Powers, S.J.; Fernandez-Garcia, N.; Urbanova, T.; Takebayashi, Y.; Seo, M.; Jikumaru, Y.; Benlloch, R.; Nilsson, O.; Ruiz-Rivero, O.; et al. Analysis of the developmental roles of the Arabidopsis gibberellin 20-oxidases demonstrates that GA20ox1, -2, and -3 are the dominant paralogs. Plant Cell 2012, 24, 941-960. [CrossRef]

61. Richards, D.E.; King, K.E.; Ait-ali, T.; Harberd, N.P. HOW GIBBERELLIN REGULATES PLANT GROWTH AND DEVELOPMENT: A Molecular Genetic Analysis of Gibberellin Signaling. Annu Rev. Plant Phys. 2001, 52, 67-88. [CrossRef] [PubMed]

62. Shwartz, I.; Levy, M.; Ori, N.; Bar, M. Hormones in tomato leaf development. Dev. Biol. 2016, 419, $132-142$. [CrossRef] [PubMed]

63. Hedden, P.; Sponsel, V. A Century of Gibberellin Research. J. Plant Growth Regul. 2015, 34, 740-760. [CrossRef] [PubMed] 
64. Phillips, A.L.; Ward, D.A.; Uknes, S.; Appleford, N.; Lange, T.; Huttly, A.K.; Gaskin, P.; Graebe, J.E.; Hedden, P. Isolation and Expression of Three Gibberellin 20-Oxidase cDNA Clones from Arabidopsis. Plant Physiol. 1995, 108, 1049-1057. [CrossRef]

65. Thomas, S.G.; Phillips, A.L.; Hedden, P. Molecular cloning and functional expression of gibberellin 2oxidases, multifunctional enzymes involved in gibberellin deactivation. Proc. Natl. Acad. Sci. USA 1999, 96, 4698-4703. [CrossRef]

66. Sun, H.; Pang, B.; Yan, J.; Wang, T.; Wang, L.; Chen, C.; Li, Q.; Ren, Z. Comprehensive Analysis of Cucumber Gibberellin Oxidase Family Genes and Functional Characterization of CsGA20ox1 in Root Development in Arabidopsis. Int. J. Mol. Sci. 2018, 19, 3135. [CrossRef]

67. Boudet, N.; Aubourg, S.; Toffano-Nioche, C.; Kreis, M.; Lecharny, A. Evolution of intron/exon structure of DEAD helicase family genes in Arabidopsis, Caenorhabditis, and Drosophila. Genome Res. 2001, 11, 2101-2114. [CrossRef]

68. Babenko, V.N.; Rogozin, I.B.; Mekhedov, S.L.; Koonin, E.V. Prevalence of intron gain over intron loss in the evolution of paralogous gene families. Nucleic Acids Res. 2004, 32, 3724-3733. [CrossRef]

69. He, H.; Liang, G.; Lu, S.; Wang, P.; Liu, T.; Ma, Z.; Zuo, C.; Sun, X.; Chen, B.; Mao, J. Genome-Wide Identification and Expression Analysis of GA2ox, GA3ox, and GA20ox Are Related to Gibberellin Oxidase Genes in Grape (Vitis Vinifera L.). Genes 2019, 10, 680. [CrossRef]

70. Pan, C.; Tian, K.; Ban, Q.; Wang, L.; Sun, Q.; He, Y.; Yang, Y.; Pan, Y.; Li, Y.; Jiang, J.; et al. Genome-Wide Analysis of the Biosynthesis and Deactivation of Gibberellin-Dioxygenases Gene Family in Camellia sinensis (L.) O. Kuntze. Genes 2017, 8, 235. [CrossRef]

71. Murase, K.; Hirano, Y.; Sun, T.P.; Hakoshima, T. Gibberellin-induced DELLA recognition by the gibberellin receptor GID1. Nature 2008, 456, 459-463. [CrossRef]

72. Fonouni-Farde, C.; Tan, S.; Baudin, M.; Brault, M.; Wen, J.; Mysore, K.S.; Niebel, A.; Frugier, F.; Diet, A. DELLA-mediated gibberellin signalling regulates Nod factor signalling and rhizobial infection. Nat. Commun. 2016, 7, 12636. [CrossRef]

73. Jin, Y.; Liu, H.; Luo, D.; Yu, N.; Dong, W.; Wang, C.; Zhang, X.; Dai, H.; Yang, J.; Wang, E. DELLA proteins are common components of symbiotic rhizobial and mycorrhizal signalling pathways. Nat. Commun. 2016, 7, 12433. [CrossRef] [PubMed]

74. Roy, S.; Liu, W.; Nandety, R.S.; Crook, A.D.; Mysore, K.S.; Pislariu, C.I.; Frugoli, J.A.; Dickstein, R.; Udvardi, M.K. Celebrating 20 years of genetic discoveries in legume nodulation and symbiotic nitrogen fixation. Plant Cell 2019. [CrossRef] [PubMed]

75. Hay, A.; Kaur, H.; Phillips, A.; Hedden, P.; Hake, S.; Tsiantis, M. The Gibberellin Pathway Mediates KNOTTED1-Type Homeobox Function in Plants with Different Body Plans. Curr. Biol. 2002, 12, 1557-1565. [CrossRef]

76. Han, Y.; Teng, K.; Nawaz, G.; Feng, X.; Usman, B.; Wang, X.; Luo, L.; Zhao, N.; Liu, Y.; Li, R. Generation of semi-dwarf rice (Oryza sativa L.) lines by CRISPR/Cas9-directed mutagenesis of OsGA20ox2 and proteomic analysis of unveiled changes caused by mutations. 3 Biotech. 2019, 9, 387. [CrossRef]

77. Chen, Z.; Liu, Y.; Yin, Y.; Liu, Q.; Li, N.; Liu, X.; Li, X.; Guo, C.; Hao, D. Development of dwarfish and yield-effective GM maize through passivation of bioactive gibberellin. Transgenic Res. 2019, 28, 589-599. [CrossRef]

78. Chen, X.; Tian, X.; Xue, L.; Zhang, X.; Yang, S.; Traw, M.B.; Huang, J. CRISPR-Based Assessment of Gene Specialization in the Gibberellin Metabolic Pathway in Rice. Plant Physiol. 2019, 180, 2091-2105. [CrossRef]

79. Garcia-Hurtado, N.; Carrera, E.; Ruiz-Rivero, O.; Lopez-Gresa, M.P.; Hedden, P.; Gong, F.; Garcia-Martinez, J.L. The characterization of transgenic tomato overexpressing gibberellin 20-oxidase reveals induction of parthenocarpic fruit growth, higher yield, and alteration of the gibberellin biosynthetic pathway. J. Exp. Bot. 2012, 63, 5803-5813. [CrossRef]

80. Mauriat, M.; Moritz, T. Analyses of GA20ox- and GID1-over-expressing aspen suggest that gibberellins play two distinct roles in wood formation. Plant J. 2009, 58, 989-1003. [CrossRef]

(C) 2020 by the authors. Licensee MDPI, Basel, Switzerland. This article is an open access article distributed under the terms and conditions of the Creative Commons Attribution (CC BY) license (http://creativecommons.org/licenses/by/4.0/). 